\title{
General Discussion to Papers of E. Bérard et al., J. G. Parish and B. Andrews et al.
}

DR P. Dollfus (Chairman). I would like from the Chair to emphasise the vocational future and training of our very severely handicapped people with these electronic devices and also the important factor of safety to keep the family together.

Prof. M. Weiss (Poland). I would like to report to you first that an environmental hostel with electronic controls was built in my country a year ago and I would like to report to you that our environmental control system for high level tetraplegics is concentrated at a hostel where we have the possibility of maintenance. It is based on single puff control so that the patient can communicate via automatically operated telephone controls, the patient's environment, bed comfort and controls of the principal sources of the patient's entertainment. The control system is demonstrated by slides.

DR Dollfus. I have been travelling through Canada and have seen the wonderful work which has been done in electronic aids for handicapped people. I do sometimes wonder what is going to happen to the people in the developing countries who cannot afford all these technical aids which we can afford in our so-called civilised countries. I think we must keep this in mind and this is why I've been pleased to see Bérard's film which should be really shown in other countries particularly in countries which need to know about what is happening and how they can help themselves. I think we should not forget about this in our research. About 2 or 3 years ago we had a demonstration here at Stoke Mandeville where Possum electronic aid was introduced in the early sixties of two tetraplegic patients showing their capabilities with a mouth stick. This was very interesting and of benefit for all of us.

Sir Ludwig Guttmann (G.B.). I'd like to endorse what the Chairman just said. Although the electronic devices are marvellous they are very expensive and we have to find ways to minimise the prices so that we can help the severely disabled people in developing countries. Of course, the situation in these countries is still so pretty bad that even the most simple appliances are needed.

DR J. WALSH (G.B.). I also would like to express my appreciation of that wonderful film. We've seen some quite complicated things this morning, but we are back to the simple apparatus which is much more acceptable to many many patients. Secondly I'd like to ask one question. I heard the word non-slip applied and used widely in gloves and on dishes, may I ask what this non-slip material is, whether it is plastic or rubber or what?

PROF. WeIss (Poland). The answer is very simple. First we are not using alphabet as the Possum had used, we use only dialler, numbers which patient can pick up with single puff. It is of course some kind of repetition we don't think that this is very different from the Possum idea. Possum was the first and we still appreciate this. But the second advantage is that our apparatus is very cheap. My electronic aid does not cost more than 300 dollars which in my country is acceptable. The third thing, I don't believe that in my part of the world such aids can be used at home, but should be used at a hostel and this was my basic point.

Dr J. G. PARRISH (G.B.) I would like to add that the trend in this country has been for these environmental control systems to become too sophisticated. The PSU3 I've tried to point out is only applicable to about 25 per cent or less of the patients who use the environmental control systems. PSUI was not even fully utilised so a simple form of equipment certainly seems to be required. I think we've gone too far in sophistication. The second point I wanted to make was that with regard to use of the equipment in the home the traumatic tetraplegia only contributed to Io per cent of my theories. The common tetraplegic patient is the patient with slowly progressive multiple sclerosis 
which is the sort of patient who is being helped in this country to stay at home and not to be admitted to hospital for long-term care or to a hostel.

DR Dollfus. May I add to this that the word hostel brings a shiver down my spine. I think we should aim to get the patient back into his family. If we can get a patient back to his family and help him to the life he wants to live then these people will not have to be in hostels. I think reintegration in the family, thanks to electronic devices if they are available should be our main aim. I would like Professor Weiss to explain what he means that these environmental controls should be reserved to a hostel only.

Prof. M. WeIss. You know the conditions are not the same in all countries. In my country everybody in the family is working and it is not easy to keep high tetraplegia at home. So either he would return to my place or would die at home. I would like to keep my efforts of saving life. At this stage of development of my own country which is developing fast and everybody is working hard, we must keep them in a hostel with all facilities.

DR E. BÉRARD (France). I should like to answer Dr Walsh's question for antislipping. It's the same one as the one used in our railways' restaurants in France, that is to say it is made of plastic which is rough.

DR J. C. Chawla (G.B.) When we were talking about various aids and devices we were talking about two types of aids and devices this afternoon, one about the independence of daily living and the other to make life fulfilled and to achieve something for the unfortunate young people who sustained tetraplegia who were university students and they want to keep their minds occupied. So one should not put an overall blanket and say that some devices should be simple. Each patient should be evaluated to ascertain what is required for that particular young person.

DR J. WALSH (G.B.). The discussion reminds me of a case which I saw about a year ago, a lady with very advanced degeneration. I recommended for her a Possum apparatus. I gave a report that every lunch time her husband came home, although she had a little dial with all the alphabet on it she couldn't do it, she could just swallow, she couldn't talk. So he picked out letters until he found the word that she wanted, for instance, if she wanted tea or she wanted something else. My recommendation was turned down because she was known as being able to communicate. I do hope that will stop. 